\title{
(4)
}

\section{Exposure of Air Pollution and its Relationship with Child Mortality in Pakistan}

\author{
Noreen Safdar ${ }^{a}$, Hala Asif ${ }^{b}$, Fatima Farooq ${ }^{c}$ \\ ${ }^{a}$ Assistant Professor, Department of Economics, the Women University Multan, Pakistan \\ E-mail: noreen.safdar@wum.edu.pk \\ ${ }^{\mathrm{b}}$ M.Phil. scholar Department of Economics, The Women University Multan, Pakistan \\ ${ }^{c}$ Assistant Professor, School of Economics, Bahauddin Zakariya University Multan, Pakistan \\ E-mail: fatimafarooq@bzu.edu.pk
}

\begin{tabular}{l}
\hline ARTICLE DETAILS \\
\hline History: \\
Accepted 26 Aug 2020 \\
Available Online 30 Sep 2020 \\
\\
Keywords: \\
Renewable Energy, Energy Use, \\
Coal Energy, Human Health, \\
Child Mortality, Pakistan
\end{tabular}

JEL Classification:

O13, $P_{22} 8, P_{36}, I 18$

DOI: $10.47067 /$ ramss.v3i2.59

\begin{abstract}
This study discovered the special effects of coal energy (a kind of non-renewable energy), Greenhouse gases, Industrialization, Population growth rate and renewable energy on human health, with key emphasis on Child Mortality rate in Pakistan. For profound practical insight, study established Auto-Regressive Distributed Lag (ARDL) model and study analyzed time series data of Pakistan for time period 1986 to 2017. The results reported that with an increase in use of coal energy mortality among children increase. In addition, results also underscored that by turning to renewable energy (energy by sun, wind and air) the health conditions could be improved as renewable energy type is environment friendly and does not produce Greenhouse gases. So, renewable energy serves as a helping factor to reduce mortality among children in Pakistan. On the other hand, coal energy is the cause of environmental degradation by increasing amount of Greenhouse gas emissions in atmosphere which in turn causes Child mortality in Islamic Republic of Pakistan.
\end{abstract}

(C) 2020 The authors. Published by SPCRD Global Publishing. This is an open access article under the Creative Commons Attribution-

NonCommercial 4.0

Corresponding author's email address: fatimafarooq@bzu.edu.pk

\section{Introduction}

Energy is considered as backbone of an economy and essential for the growth and development. Two kinds of energy is used worldwide; renewable energy and non-renewable energy. Mostly renewable energy like Hydro energy, solar energy and nuclear energy sources are fastest growing energy sources but these are not most widely used energy sources as compared to nonrenewable energy sources. The renewable energy sources usage is increasing 2 percent every year. As the world's population is increasing so, the demand for energy is also increasing as per this ratio. Mostly in developed countries, they moved to renewable energy from non-renewable energy sources 
that are environment friendly as they damage environment by less ratio. Developing countries are also moving from non-renewable energy sources to renewable energy sources.

Non-renewable energy sources like coal and fossil fuel energy are most widely used energy sources in the world. Approximately 80 percent of world energy is supplied in the form of fossil fuel energy. Natural gas, Liquefied Petroleum Gas (LPG) and Coal are some of the sources to produce fossil fuel energy. The most widely growing up fossil fuel energy is natural gas, but in Pakistan coal power-plants are also operating, and the use of coal energy is also increasing. Coal contributes to Green-house Gas emissions. Non-renewable energy contributes to Green-house Gas emissions which is the combination of Carbon Dioxide $\left(\mathrm{CO}_{2}\right)$ and other energy related emissions.

Other types of fossil fuels energies like dung, wood and crop waste are also used widely in our rural areas. The population in our rural areas is mostly poor and they do not have even proper energy sources and they are still engaged in using fossil fuel energy for cooking, cleaning, heating and other household activities. In these areas, the women spend most of their time in kitchen and children also spend most of time with their mothers in kitchen. As fossil fuel energy is the major kind of non-renewable energy and not safe for human health as it promotes serious and ill health outcomes, so the women and children are more expose to vulnerability.

The mortality due to lung cancer and other types of cancer is found in West Virginia, United States of America and cause of cancer is coal mining. The areas where coal mining is high as compared to areas where there low coal mining is observed have high cancer mortality rates [Hendryx (2010)]. The coal mining is a process of getting non-renewable energy from coal and this process may generate toxic elements like copper, arsenic, nickel and beryllium etc. and these elements may mix in water and the contaminated water causes many diseases especially cancer is the negative health outcome that may cause due to polluted water and at other side air pollution is also generated by mixing other harmful elements into air which are generated in coal mining process.

Biomass fuel is most widely used cooking fuel used by developing countries like Pakistan. When the biomass fuel is burnt in raw form the harmful substances and gases generates like Carbon Dioxide Gas, Hydrocarbons, Carbon Monoxides, Sulphur Dioxide and Nitrates etc. that causes child mortality in host country and also causes low birth weight, adverse pregnancy outcomes because mostly women and children spend their time in kitchen in cooking hours. Respiratory disease in children is found in rural areas of host country. The biomass fuel generates 63 percent more particulate matters as compared to Liquefied Petroleum Gas [Janjua et al. (2012)].

Both renewable and non-renewable energy poses some impacts on human health. Renewable energy is beneficial for human health as the mortality rate and tuberculosis incidence declined in Sub-Saharan Africa by turning to renewable energy from biomass energy. The industrialization is the cause of environmental degradation and coal energy is used mostly by rural population, so the health conditions are not good because both industrialization and coal combustion is dangerous for respiratory health as it is the cause of Tuberculosis and it also causes mortality [Hanif (2018)].

\section{Literature Review}

Miller et al. (2007) estimated long-term exposure to air pollution and their relationship to women's cardiovascular diseases. The long-term exposure of air pollutants from energy use caused 
an increase in mortality rates and there was also an increase in hospitalization due to cardiovascular disease mostly among women. It can be concluded by this study that long-term exposure of the air pollutants by energy use were the cause of cardiovascular disease mostly among women and in turn it caused the deaths among postmenopausal women.

Woodcock et al. (2009) estimated human health benefits of the strategies of reducing greenhouse gas emissions from urban transport for London, United Kingdom, Dehli, India. The results showed that besides uncertainties, the health and climate effect of the strategies of reducing greenhouse gas emissions was positive and these strategies benefit human health so these strategies were highly encouraged as they were proved useful for climate and in this way health benefits could be gained.

Hendryx and Zullig (2009) examined the association between higher coronary heart disease and heart attack morbidity in the Appalachia and coal mining activities in coal mining areas. The health conditions of the people were documented poor in the study because of coal mining activities in the Appalachia as compared to other parts of the region. The research revealed that pollution from coal mining was the cause of Heart diseases, mortality and morbidity.

Fatmi et al. (2010) examined the association between biomass energy in household's use and its impacts to human health, health burden and air pollution for Pakistan. The results of this study clearly revealed that there was a positive relation between ill health effects and biomass fuels and air pollution. The policy measures suggested that there should be improvement in energy use and biomass fuel usage should be minimized so that, air pollution and ill health effects could be minimized.

Hyndrex et al. (2010) explored the correlation between coal mining activities and the causes of mortality from cancer in West Virginia, United States of America. Cancer mortality in West Virginia was recorded higher than other areas of United States of America which had no coal mining. Ordinary Least Square Model were used. The results showed that in some cases cancer mortality was caused by coal-mining, but it is suggested that more findings were needed.

Colbeck et al. (2010) estimated the relation between the nitrogen dioxide and household's fuel in Pakistan for the time period 2005-2007. Biomass fuel was used in rural site and biomass fuel as well as natural gas was used in urban site. The result indicated that overall selection fuel caused an increase in nitrogen dioxide in air that caused serious harms to human health especially women and children affected most.

Grieshop et al. (2011) evaluated the health benefits as well as climate benefits of replacement of cookstove options. The results of this study revealed the fact that that kind cookstoves that used biomass produced more air pollution as compared to cookstoves that used liquefied petroleum gas and kerosene etc. The policy measures indicated that the biomass cookstove should be replaced with kerosene and liquefied petroleum gas stoves and other cleanest stoves that used renewable biomass, to get better climate and to get health benefits.

Kim et al. (2011) investigated the correlation between diseases and air pollution due to the usage of biomass fuels to get energy. The results of this study demonstrated that use of biomass as a fuel was proved dangerous to human health of not only for children but also for adults and it was the 
cause of mortality and morbidity. The policy measures suggested that there should be use of LPG, Kerosene etc. instead of biomass.

Ahern et al. (2011) evaluated the association between the mountaintop mining and birth defects among live births in central Appalachia for the time period 1996-2003. The Poisson Regression Model was being used to calculate the crude and adjusted estimates in this analysis. The results revealed that there were more birth defects being estimated in mountaintop mining areas than non-mountaintop mining areas of Appalachia.

Janjua et al. (2012) examined the use of biomass fuel and Acute Respiratory illness among children less than 5 years in rural Pakistan for the year 2007. Poisson Regression Model was used to access the association between the use of Biomass fuel and Acute Respiratory Infection among children. The results indicated that the Acute Respiratory Infection was presented among children who accompanied their mothers during cooking and where the biomass such as fossil fuels was used as cooking fuel.

Vieux et al. (2012) investigated the correlation between the greenhouse gas emissions and self-selected individual's diet. They took the data of France for analysis in this studyThe Linear Regression model was being used for analysis. The results showed that if food items were substituted like the meat was replaced with vegetables and fruits, the health benefits could be gained but it is not necessary that food associated greenhouse gas emission would be decreased.

Niaz et al. (2016) investigated the Particulate Matters $\mathrm{PM}_{10}$ and $\mathrm{PM}_{2.5}$ and they compared both by taking the data of two different countries China and Pakistan.. The results revealed that both the $\mathrm{PM}_{1.0}$ and $\mathrm{PM}_{2.5}$ were high in winter season as compared to summer season, and the variations in PM level were higher in Dalian as compared to Faisalabad due to more energy use.

Hanif (2018) estimated the habits of energy consumption by humans and its impacts on human health in Sub-Saharan Africa for the time span from 1995 to 2015. In the study the panel data of the 34 lower-middle income countries was used for analysis The results of this study declared that the use of both solid fuels and fossil fuels for cooking, heating and lightening etc in Sub-Saharan Africa caused Tuberculosis among human beings and also these fuels reduced life expectancy as these caused mortality.

Safdar et al. (2019) investigated the impact of energy consumption, environmental degradation on employment in 50 developing countries over the period of 1990 to 2016 . By using PMG method, the study came to conclusion that energy use and environmental degradation is great threat to human health and quality of life. The study suggested that these countries should adopt renewable energy sources to meet their energy demand. The dependence on renewable energy sources will enhance growth and other economic opportunities without affecting human health and environment.

Safdar et al. (2020) found the impact of coal energy (a kind of non-renewable energy), renewable energy, Greenhouse gases, industrialization, population growth and environmental degradation and on the health of human beings, with the key emphasis on Tuberculosis incidence in Pakistan for the time span 1986 to 2017. The results reported that with an increase in the usage of coal energy, the incidence of Tuberculosis also increased. In addition, the results also highlighted that by turning to the renewable energy (energy by sun, wind and air) the health could be improved 
as the renewable energy is environment friendly and it does not generate greenhouse gases and it also does not cause environmental degradation.

\section{Data and Methodological issues}

This segment defines the variables that are used to find out impacts of the energy use on health of human beings in Pakistan. On the basis of the theoretical and empirical consequence, the variables are being chosen. The Child Mortality is used as the dependent variable and Renewable energy, Coal consumption, Greenhouse Gas, Industrialization, Population are the independent variables.

\subsection{Time Period}

Time series data of Pakistan for time span 1975-2017 is being used to check the association among dependent and the explanatory variables.

\subsection{Data Sources}

The study is grounded on the secondary data type and the data is collected from WDI (World Development Indicator 2017) and Economic Survey of Pakistan.

\subsection{Model Specification:}

This study shows the effects of energy usage on human health. Model specification is as follows.

$$
\mathrm{CHM}=f(\mathrm{ENG}, \mathrm{CLC}, \mathrm{GHG}, \mathrm{IND}, \mathrm{POP})
$$

Here, Child Mortality is the function of Renewable energy use, Coal consumption, Greenhouse Gas, Industrialization and Population.

Whereas,

$$
\mathrm{LCHM}=\beta \mathrm{o}+\beta_{1}(\mathrm{LENG})+\beta 2(\mathrm{LCLC})+\beta 3(\mathrm{LGHG})+\beta 4(\mathrm{LIND})+\beta 5(\mathrm{LPOP})+\varepsilon
$$

$\mathrm{LCHM}=\log$ of Child Mortality

LENG $=\log$ of Renewable Energy use

LCLC $=\log$ of Coal Consumption

LGHG $=\log$ of Greenhouse Gas

LIND: log of Industrialization

LPOP: log of Population

Here $\beta$ 's are the elasticities. Keeping in view of above model we evaluated the model to satisfy the hypothesis of study that is; the coal energy use is positively related to Child Mortality and renewable energy use is negatively related to Child Mortality. Industrialization, Greenhouse gas and industrialization are positively related to Child Mortality and negatively or positively related to Population.

\section{Results and Discussion}

This segment gives unit root and ARDL estimates of this model. The results are as follows:

\subsection{Unit Root test:}

To check that data is stationary or not we use panel unit root test presented by Dickey and Fuller. The results attained by this test are as follows. 
Table 1: Unit Root Results:

\begin{tabular}{|l|l|l|l|l|l|}
\hline Variables & \multicolumn{2}{l|}{ Level } & \multicolumn{2}{l|}{$1^{\text {st }}$ difference } & Results \\
\hline & intercept & $\begin{array}{l}\text { Trend and } \\
\text { intercept }\end{array}$ & intercept & $\begin{array}{l}\text { Trend and } \\
\text { intercept }\end{array}$ & Conclusion \\
\hline CHM & ---- & --- & $\begin{array}{l}-3.5684 \\
(0.0000)\end{array}$ & ---- & I (1) \\
\hline ENG & ---- & ---- & $\begin{array}{l}-2.960 \\
(0.002)\end{array}$ & ----- & I (1) \\
\hline CLC & ---- & ----- & $\begin{array}{l}-2.992 \\
(0.0001)\end{array}$ & ----- & I (0) \\
\hline IND & ----- & ----- & $\begin{array}{l}-2.9678 \\
(0.0000)\end{array}$ & ----- & I (1) \\
\hline GHG & ----- & ----- & $\begin{array}{l}-2.9639 \\
(0.0000)\end{array}$ & ----- & I (1) \\
\hline POP & ----- & ----- & $\begin{array}{l}-2.9639 \\
(0.0000)\end{array}$ & ----- & I (1) \\
\hline
\end{tabular}

The result shows the mixed order of the integration so, we used Auto Regressive Lag Model (ARDL) to find the relationship between variables we used in our model. Before going to discuss the ARDL results, it is necessary to find the long run assessment of association between series of variables, the bound test estimation is demonstrated for this purpose.

Table 2 BOUND TESTING:

\begin{tabular}{|l|l|l|l|l|l|}
\hline \multicolumn{3}{|c|}{ At 5\% significance level } & \multicolumn{2}{l|}{ At 10\% significance level } \\
\hline Models & F-statistics & Lower bound & Upper bound & Lower bound & $\begin{array}{l}\text { Upper } \\
\text { bound }\end{array}$ \\
\hline Model 2 & 22.93415 & 2.62 & 3.79 & 2.26 & 3.35 \\
\hline
\end{tabular}

Source: estimated by author using E-views 9

In our model, the F-statistics value is greater than the $5 \%$ value of upper bound and $10 \%$ value of upper bound that are 3.79 and 3.35 respectively so long run relationship exists in our second model.

\subsection{ARDL Estimates of Model:}

Table 3 gives the results of short run and long run of ARDL 
Table 3: ARDL Estimates of Model:

\begin{tabular}{|l|l|l|l|l|}
\hline \multicolumn{5}{|c|}{ ARDL Long Run Results } \\
\hline Variables & Coefficient & Standard Error & t-statistics & Probability \\
\hline ENG & -0.1489 & 0.1611 & 0.9241 & 0.0366 \\
\hline CLC & 0.0655 & 0.0199 & 3.2953 & 0.0036 \\
\hline GHG & 0.1501 & 0.1013 & 1.48171 & 0.0154 \\
\hline IND & 0.0870 & 0.0280 & 3.1023 & 0.0056 \\
\hline POP & 0.9039 & 0.122 & -7.3931 & 0.0000 \\
\hline \multicolumn{5}{|l|}{ ARDL Short Run Results } \\
\hline Variables & Coefficients & Standard Error & t-statistics & Probability \\
\hline D(CHM(-1)) & 0.7705 & 0.0428 & 17.9810 & 0.0000 \\
\hline D(ENG) & -0.0153 & 0.0164 & -0.9384 & 0.3592 \\
\hline D(CLC) & 0.0008 & 0.0017 & 0.4952 & 0.6258 \\
\hline D(CLC(-1) & -0.0060 & 0.0022 & -2.6397 & 0.0157 \\
\hline D(GHG) & 0.0155 & 0.0094 & 1.6509 & 0.1144 \\
\hline D(IND) & 0.0089 & 0.0033 & 2.7072 & 0.0136 \\
\hline D(POP) & -0.0934 & 0.0139 & -6.7198 & 0.0000 \\
\hline CointEq(-1) & -0.1033 & 0.0141 & -7.2946 & 0.0000 \\
\hline
\end{tabular}

In our model we take child Mortality as dependent variable that we used as a proxy of human health. The renewable energy use has a negative and significant relationship with Child mortality. The probability value of renewable energy use is 0.0366 so, it has a statistically significant relation with Child mortality. 1 percent increase in renewable energy use causes -0.14 percent decline in Child mortality. Renewable energy like wind, air and solar energy do not harm human health and it is considered as environment friendly energy so, the Child mortality reduce as the usage of renewable energy increased. Our results are supported by the contribution of [Hanif (2018)].

The Coal energy consumption has a positive and significant relation with Child mortality. The probability value of Coal energy consumption is 0.0036 so, it has statistically significant relationship with Child mortality. 1 percent increase in coal energy consumption leads to 0.06 percent increase in Child mortality. As coal is used as cooking fuel in our rural areas so it causes air pollution which is dangerous for women and especially for the health of children because they spend most of their time in kitchen in cooking hours to accompany their mothers. Our result supports the work of [Colbeck (2007); Hendryx et al. (2008); Barnes et al. (2009)]. According to World Health Organization report, the child mortality is caused by using coal as a fuel for cooking and heating [WHO, (2006)].

The Greenhouse Gases emissions have positive and significant relationship with Child mortality. The probability value of Greenhouse Gases is 0.0036, it has statistically significant relationship with Child Mortality. 1 percent increase in Greenhouse Gases leads to 0.15 percent increase in child mortality. The amount of non-renewable energy used by population is increasing as the population is rising at rapid rate. So, the amount of Greenhouse Gases in atmosphere is also uprising which causes rise in death rates. Our results are supported by the work of [Dockery et al. 
(1993); Bailis et al. (2005)].

The Industrialization has a positive and significant relation with child mortality. The probability value of Industrialization is $0.0056 \mathrm{so}$, it has significant relation with child mortality. 1 percent increase in Industrialization causes 0.08 percent increase in child mortality. Energy is used in all sectors of an economy, from livestock to in industries the use of energy cannot be avoided which in turn causes adverse health outcomes especially it causes mortality due to harmful emissions due to non-renewable energy use. Our results are supported by the contribution of [Hanif (2018)].

The Population has a positive and insignificant relation with child mortality. The probability value of Population is 0.0000 so it has statistically significant relation with child mortality at 5 percent level of significance and also at 10 percent significance level. 1 percent increase in population causes 0.90 percent increase in child mortality. As population of a country increases, the energy use also increases at same or more ratio. So, the mortality rate also increases as the non-renewable energy is the cause of air pollution which in turn causes mortality. Our result is supported by the studies of [Larson et al. (2000); Hanif (2018)].

\subsection{Diagnostic Analysis of the Model:}

We estimate the serial correlation and heteroskedasticity of model. Different methods are applied to check the heteroskedasticity and auto-correlation in the mode, most widely hired methods are Breush-Godfrey correlation LM test and heteroskedasticity diagnostic test.

Table 4: Auto correlation and Heteroskedasticity diagnostics

\begin{tabular}{|l|l|l|}
\hline Name of test & F-statistics value & Probability \\
\hline \multicolumn{2}{|c|}{ Model 2 } \\
\hline $\begin{array}{l}\text { Breush-Godfrey } \\
\text { correlation LM test }\end{array}$ & 0.29861 & 0.9706 \\
\hline Heteroskedasticity & 1.590047 & 0.1857 \\
\hline
\end{tabular}

Source: estimated by author using E-views 9.

In this model, the F-statistics value of serial correlation is 0.29861 and its probability is 0.9706 which is greater than 0.05 so it is statistically significant. We reject our null hypothesis that there is serial correlation and accept our alternative hypothesis that there is no serial correlation exists in our model. The F-statistics value of heteroskedasticity is 1.590047 and its probability is 0.1857 that is greater than 0.05 . We reject our null hypothesis that there is heteroskedasticity exists and we accept our alternative hypothesis that there is no heteroskedasticity exists in our model.

\section{Conclusion and Policy Implications}

The basic purpose of given research is to elaborate the impact of energy use on human health. For this purpose, the secondary type of data of Pakistan is taken from different sources e.g. WDI and Economic Survey of Pakistan from the time period 1996-2017.

This study documented both kind of energy usage by industrial as well as household sector and also deliberated the effects of both kinds of energies on human health. Energy obtained by renewable energy sources (sun, wind, air) provides no harms to human health as it does not increase Greenhouse Gas emissions. But energy obtained by non-renewable energy sources especially by 
using of coal, is harmful for environment as well as for health of residents of the host country. In host country, most of population lives in rural areas and fulfill most of their energy needs by burning coal. It is exact that in host country, both types of energy sources are being used to fulfill need of energy so, both kinds of energy are examined in this study. It is obvious by many studies that the coal generated pollutants can travel rapidly as compared to other air pollutants.

Mortality is common in the areas where there the coal is used to get energy, especially in rural areas of host country the coal energy is used for heating, lightening and cooking food. Mostly women are engaged in these activities and their children accompany them in kitchen during cooking hours. It is proved from earlier studies that coal generates a large amount of Greenhouse Gases and fly ash and these are the cause of mortality among residents. So, coal used in getting energy is the cause of mortality among women and especially children are most exposed to danger. Coal used by households as well as by industrial sector causes the mortality among children. Our results are supported by [Hendryx et al. (2008)].

In host country, not only the non-renewable energy is used but also the renewable energy is used by all sectors. The renewable energy guarantees no fly ash and no Greenhouse Gas emissions. This analysis found that there is a negative relation between child mortality and renewable energy use, by the consumption of renewable energy the mortality of children is not increased. Our result is supported by the research of Hanif (2018).

\section{Policy Recommendations}

Here are some predictions that we present after examining current situation of the host country. Some of these forecasts are as follows.

- Analyzing last year's approximations, the use of coal will increase in host country, as in the host country coal power plant is built in Sahiwal in 2017.

- Although cheapest source of energy in the host country is coal. So, the use of coal will also increase because most of the population is poor and there is no close substitute that is cheap as coal.

- There is very massive increase in the quantity of Greenhouse Gas emissions in the host country by 1990 to onwards. Greatest source of theses emissions is energy sector. So as population is increasing at rapid rate so, energy use will also raise and Greenhouse Gas emissions will also grow.

- As demand for coal energy will upsurge, the Greenhouse Gas emissions will also generates in large quantity and will damage environment and mortality among children will be caused due to non-renewable energy usage.

Now here are some of policy-measures that should be useful for policy makers for making policies that may prove supportive to reduce health damage caused by the energy usage. Some of the recommendations are as follows.

- We should move to renewable energy from non-renewable energy sources as health cost of non-renewable energy is very high.

- Environment friendly energy production techniques must be implemented to reduce air pollution and Greenhouse Gas emissions.

- To improve health conditions of the people living in rural areas, Government should provide cheap and renewable energy to residents; this step will prove beneficial for rural population if they move to renewable energy from the biomass combustion. 
- In industrial sector, access to the renewable energy should be inexpensive so this sector could turn to renewable energy and Greenhouse Gas emissions could be decreased.

- It is certified that best fuel selection to get energy should be established among energy consuming sectors, so they could turn to environment friendly energy sources and burden of disease could be lessened.

- It is recommended that access to renewable energy should be cheaper than any nonrenewable energy source so urban and rural population could gain its paybacks and the burden of disease could be diminished.

- It is suggested to improve ventilation quality, it will valuable for improvement of indoor air quality.

\section{References:}

Ahern, M. M., Hendryx, M., Conley, J., Fedorko, E., Ducatman, A., \& Zullig, K. J. (2011). The association between mountaintop mining and birth defects among live births in central Appalachia, 1996-2003. Environmental research, 111(6), 838-846.

Bailis, R., Ezzati, M., \& Kammen, D. M. (2005). Mortality and greenhouse gas impacts of biomass and petroleum energy futures in Africa. Science, 308(5718), 98-103.

Barnes, B., Mathee, A., Thomas, E., \& Bruce, N. (2009). Household energy, indoor air pollution and child respiratory health in South Africa. Journal of Energy in Southern Africa, 2o(1), 4-13.

Colbeck, I., Nasir, Z. A., Ali, Z., \& Ahmad, S. (2010). Nitrogen dioxide and household fuel use in the Pakistan. Science of the total environment, 409(2), 357-363.

Dockery, D. W., Pope, C. A., Xu, X., Spengler, J. D., Ware, J. H., Fay, M. E., ... \& Speizer, F. E. (1993). An association between air pollution and mortality in six US cities. New England journal of medicine, 329(24), 1753-1759.

Fatmi, Z., Rahman, A., Kazi, A., Kadir, M. M., \& Sathiakumar, N. (2010). Situational analysis of household energy and biomass use and associated health burden of indoor air pollution and mitigation efforts in Pakistan. International journal of environmental research and public health, 7(7), 2940-2952

Grieshop, A. P., Marshall, J. D., \& Kandlikar, M. (2011). Health and climate benefits of cookstove replacement options. Energy Policy, 39(12), 7530-7542.

Hendryx, M. (2008). Mortality rates in Appalachian coal mining counties: 24 years behind the nation. Environmental Justice, 1(1), 5-11.

Hanif, I. (2018). Energy consumption habits and human health nexus in Sub-Saharan Africa. Environmental Science and Pollution Research, 25(22), 21701-21712.

Hendryx, M., \& Zullig, K. J. (2009). Higher coronary heart disease and heart attack morbidity in Appalachian coal mining regions. Preventive Medicine, 49(5), 355-359.

Hendryx, M., Fedorko, E., \& Anesetti-Rothermel, A. (2010). A geographical information system-based analysis of cancer mortality and population exposure to coal mining activities in West Virginia, United States of America. Geospatial Health, 243-256.

Janjua, N. Z., Mahmood, B., Dharma, V. K., Sathiakumar, N., \& Khan, M. I. (2012). Use of biomass fuel and acute respiratory infections in rural Pakistan. Public health, 126(10), 855-862.

Kim, K. H., Jahan, S. A., \& Kabir, E. (2011). A review of diseases associated with household air pollution due to the use of biomass fuels. Journal of hazardous materials, 192(2), 425-431.

Larson, B. A., \& Rosen, S. (2000). Household benefits of indoor air pollution control in developing countries. USAID/WHO Global Technical Consultation on the Health Impacts of Indoor Air Pollution and Household Energy in Developing Countries, Washington, DC David Pearce, 57.

Miller, K. A., Siscovick, D. S., Sheppard, L., Shepherd, K., Sullivan, J. H., Anderson, G. L., \& Kaufman, 
J. D. (2007). Long-term exposure to air pollution and incidence of cardiovascular events in women. New England Journal of Medicine, 356(5), 447-458.

Niaz, Y., Zhou, J., Nasir, A., Iqbal, M., \& Dong, B. (2016). Comparative study of particulate matter (PM 10 and PM 2.5) in Dalian-China and Faisalabad-Pakistan. Pakistan Journal of Agricultural Sciences, 53(1).

Vieux, F., Darmon, N., Touazi, D., \& Soler, L. G. (2012). Greenhouse gas emissions of self-selected individual diets in France: changing the diet structure or consuming less?. Ecological economics, 75, 91-101.

Safdar, N., Asif, H., \& Farooq, F. (2020). Energy Use and Human Health Nexus in Pakistan. Review of Economics and Development Studies, 6(3), 661-674.

Safdar, N., Chaudhry, I. S., \& Chaudhry, M. O. (2019). Energy Consumption, Environmental Degradation and Economic Growth in Developing Countries. Pakistan Journal of Social Sciences (PJSS), 39(2).

Woodcock, J., Edwards, P., Tonne, C., Armstrong, B. G., Ashiru, O., Banister, D., ... \& Franco, O. H. (2009). Public health benefits of strategies to reduce greenhouse-gas emissions: urban land transport. The Lancet, 374(9705), 1930-1943. 


\section{Appendix}

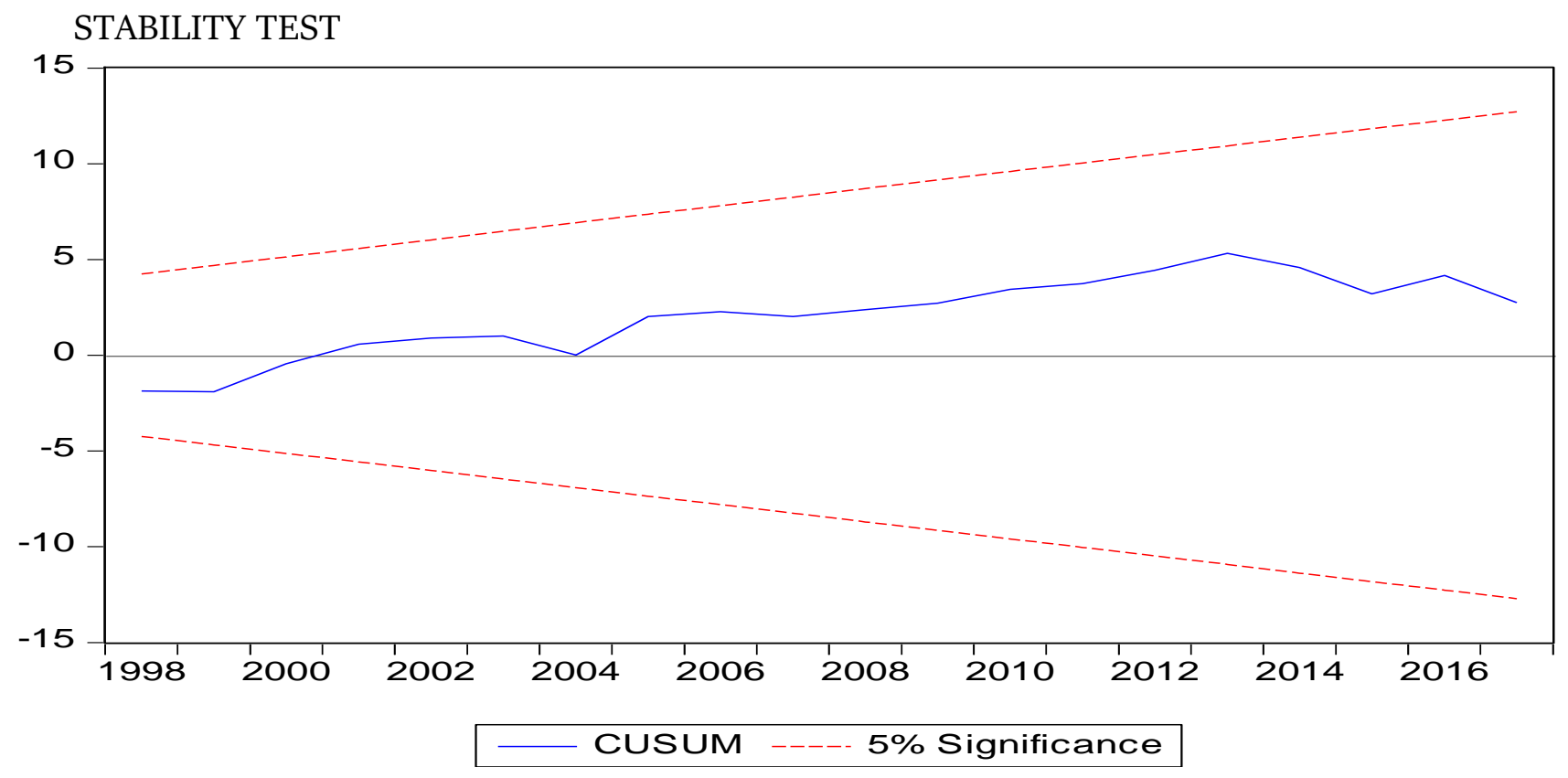

Figure 1. Plot of Cumulative Sum of Square of Recursive Residuals.

Source: estimated by author using E-views 9.

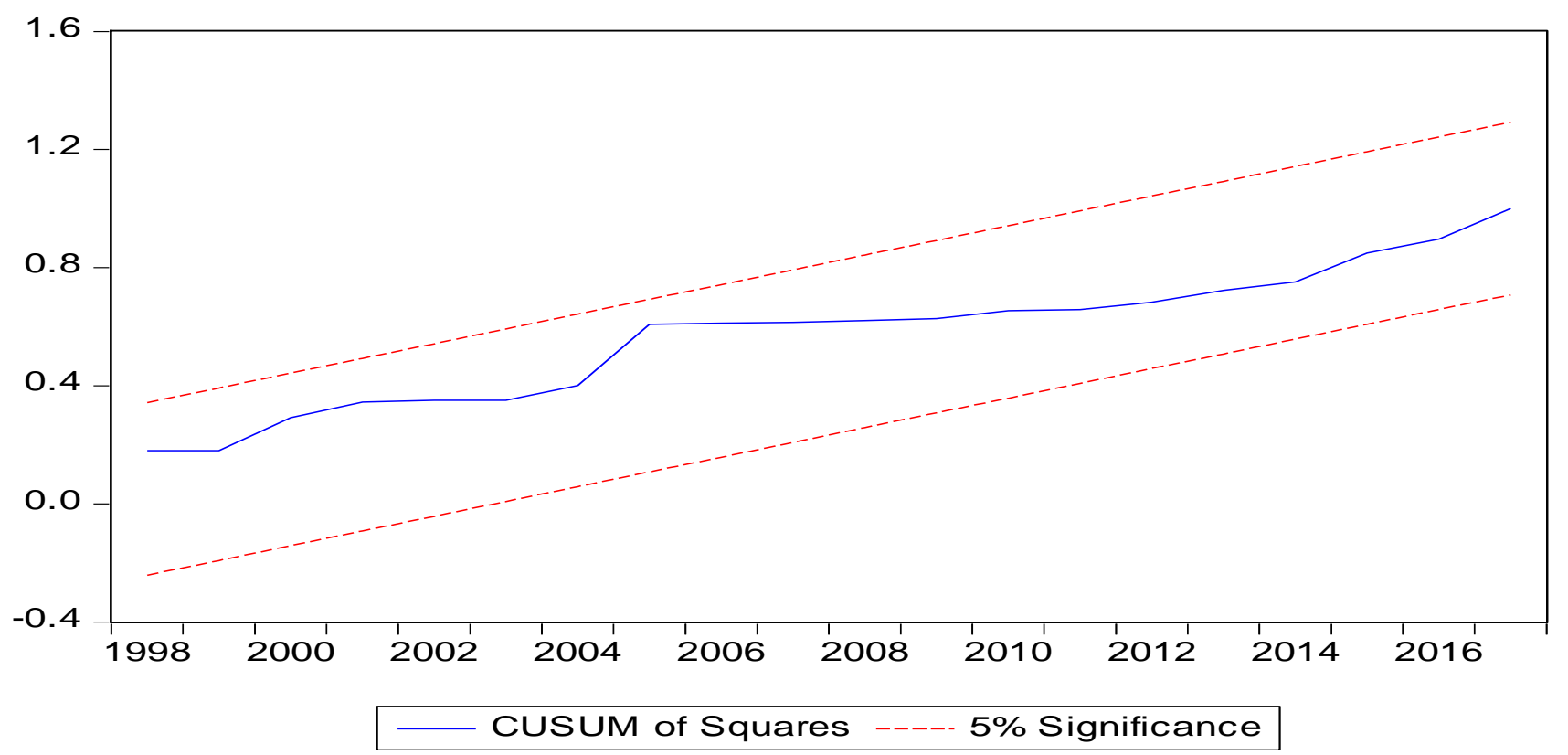

Figure 2 Plot of Cumulative Sum of Square of Recursive Residuals.

Source: estimated by author using E-views 9.

For both models we hired stability diagnostic. The figures got by using CUSUM and CUSUMSQ indicates that our both models are significant and stable. For both models the CUSUM and CUSUMSQ test lies inside critical bound at 5\% significance level. 